\title{
Moisture Sources in Relation to Conidial Dissemination and Infection by Cladosporium carpophilum Within Peach Canopies
}

\author{
Z. Lan and H. Scherm
}

Department of Plant Pathology, University of Georgia, Athens 30602.

Accepted for publication 20 August 2003.

\begin{abstract}
Lan, Z., and Scherm, H. 2003. Moisture sources in relation to conidial dissemination and infection by Cladosporium carpophilum within peach canopies. Phytopathology 93:1581-1586.

Cladosporium carpophilum, the causal agent of peach scab, overwinters in lesions on 1-year-old twigs, from which conidia infect the developing fruit during spring and early summer. Twig lesions constitute the sole source of initial inoculum; therefore, the mode of dissemination of conidia from such lesions to the fruit is of considerable interest. In a 4 -year study, we determined the relative importance of air- versus waterborne conidia and their interaction with different fruit wetness sources (splash, twig runoff, and dew) in a peach orchard with areas that had been treated or not treated with fungicide the previous year. The rareness of scab twig lesions in the previously sprayed trees implied that fruit infection in these trees would occur primarily by airborne conidia from unsprayed trees nearby (located within the same tree row or the adjacent row). In the unsprayed areas, additional infections could occur by shortdistance waterborne dissemination of conidia from locally abundant twig lesions via splashing or runoff. Beginning at calyx fall, individual fruit

shields were adjustable, allowing rain or dew to be excluded selectively. Various combinations of the shield and wick treatments were implemented in the previously sprayed and unsprayed areas, and statistical comparison of fruit scab severity between individual treatments by linear contrasts allowed us to untangle the relative contributions of the various sources of inoculum and fruit wetness. Results showed that aerial dissemination of conidia contributed little to fruit scab development, even in the presence of fruit surface wetness caused by splashing, runoff, or dew. In contrast, waterborne conidia contributed considerably and significantly $(P<0.0001)$ to disease development. This was due primarily to the importance of splash in disseminating conidia from twig lesions to the fruit, given that exclusion of splashing via rain shields decreased disease severity by $>90 \%$. Runoff water from the twig to the fruit via the peduncle also contributed to scab development, as evidenced by the fact that exclusion of runoff by cotton wicks reduced disease severity by 31.6 to $44.9 \%$; however, this effect was not always statistically significant. The exclusion of dew did not reduce scab severity $(P>0.4)$, suggesting that it played a limited role in infection in the presence of other fruit wetness sources.
\end{abstract} were protected from splash by rain shields, protected from runoff by cotton wicks placed proximal to the peduncle, or left untreated. Rain
Additional keywords: Fusicladosporium carpophilum, Prunus persica.
The hyphomycete Cladosporium carpophilum (syn. Fusicladosporium carpophilum) (21) causes scab, one of the most important and costly diseases of peach (Prunus persica) and other stone fruits in the southeastern United States $(8,12,19)$. Infection by the pathogen leads to the formation of dark, raised lesions that reduce fruit quality. In severe cases, coalescence of scab lesions can result in fruit cracking, thereby increasing susceptibility to rot pathogens.

C. carpophilum overwinters in lesions on 1-year-old twigs, and conidia produced on these lesions during spring and early summer infect the developing fruit and newly expanding shoots (12). Conidial production on twig lesions commences around bloom, peaks around calyx split, and reaches $90 \%$ of the cumulative seasonal total within 10 weeks of bloom $(3,24)$. Thus, most fruit infections occur during early fruit development. Infections in the fruit maturation phase are of limited importance due to diminished inoculum availability in conjunction with the long latent period of the disease.

Twig lesions constitute the sole source of initial inoculum; therefore, the mode of dissemination of conidia from such lesions to fruit is of considerable interest. In the first detailed study of the epidemiology of peach scab in the southeastern United States, Keitt (12) examined conidial release from sporulating peach twigs and bean pod cultures in the laboratory and noted that conidia were detached from conidiophores only following wetting. Simu-

Corresponding author: H. Scherm; E-mail address: scherm@uga.edu

Publication no. P-2003-1020-04R

(C) 2003 The American Phytopathological Society lated wind resulted in very limited liberation of conidia, even when conidia previously had been detached by wetting and then were allowed to dry. Detailed field observations by the same author revealed that scab was most severe on fruit located near twig lesions, particularly if the twig was sloping from the lesion to the fruit. This led him to conclude that most infections occur during rain, when wetting detaches conidia and runoff water carries them from the lesion to the fruit surface via the peduncle (12). A field study by Lawrence and Zehr (16) supported the waterborne nature of conidial dissemination by documenting the presence of conidia in runoff water from peach twigs with scab lesions during rain. However, spore-trapping experiments by these authors also documented the presence of large numbers of conidia of a benomyl-resistant Cladosporium sp. (presumed to be $C$. carpophilum) in the orchard air in the absence of rain. Such airborne conidia were inferred to infect during dew periods in the absence of rain (16). In a controlled-environment experiment by another investigator (6), dry release of conidia of $C$. carpophilum from lesions on detached infected fruit was observed only during rapid decreases of relative humidity $(\mathrm{RH})$ to levels of $<40 \%$ from near saturation, especially during exposure to red-to-infrared radiation. This finding implies that conidia could become airborne in conditions of rapid drying around sunrise.

The studies cited above provide conflicting information regarding the relative importance of air- versus waterborne dissemination of conidia of $C$. carpophilum. Similar inconsistencies exist for other Cladosporium spp., such as $C$. caryigenum, $C$. cucumerinum, C. allii, C. allii-cepae, and $C$. herbarum, for which runoff washing (15), aerial discharge following a rapid decrease in $\mathrm{RH}$ 
$(5,7,11,20)$, or a combination of these factors (22) have been implicated in conidial dissemination.

The observation of increased peach scab severity during rainy growing seasons $(12,14,23)$ appears to support the notion that waterborne conidial dissemination plays a major role in disease development. However, frequent rainfall also leads to prolonged fruit wetness periods, thereby favoring infection by conidia that may have been deposited via aerial dissemination. The purpose of this study was to determine the relative contribution to fruit scab development of various means of conidial dissemination (rain splash, twig runoff, and aerial dispersal) in the presence of different fruit wetness sources (splash, runoff, and dew). Studies were carried out in orchard conditions where conidia moisture from different sources, or both were excluded selectively from individual fruit. An abstract summarizing preliminary results has been published (13).

\section{MATERIALS AND METHODS}

Year 2000 experiment. The experiment was carried out in a planting of mature peach trees, cv. Blake, at the University of Georgia Horticulture Farm near Athens. Trees were spaced $3.0 \mathrm{~m}$ (in row) and $6.1 \mathrm{~m}$ (between row) apart and trained to a four-scaffold vase. The block containing the trees received no fungicide sprays during the 1999 and 2000 seasons. At calyx fall (midApril), 200 individual fruit (no more than four fruit per tree) were selected randomly and subjected to treatments that prevented rain splash or twig runoff from reaching the fruit (Fig. 1). Splash was excluded by attaching rain shields, made from plastic petri dish lids (100 by $15 \mathrm{~mm})$, to the twig with steel wires, such that the shield was positioned above the fruit. Shields were spray-painted white to minimize heating during exposure to sunlight, and the point of attachment to the twig was downstream of the fruit, so that the wire would not interfere with twig runoff. Runoff was prevented from reaching the fruit by fastening cotton wicks, made from alcohol burner wicks (18 cm long), to the twig 4 to $5 \mathrm{~cm}$ adjacent to the fruit peduncle in upstream position; on horizontally oriented twigs, wicks were attached on both sides of the fruit. There were four treatment combinations in a two-factorial arrangement: presence or absence of shields $\times$ presence or absence of wicks. Each of the four treatments consisted of 50 fruit, but some fruit loss due to brown rot (caused by Monilinia fructicola) and other causes occurred throughout the season. At harvest (firm-ripe stage of fruit maturity), the scabbed area on each fruit was determined by counting the number of lesions per fruit separately for up to five different lesion-size classes, multiplying the number of lesions in each size class with the area of a typical lesion in this class (based on average diameters determined with a digital caliper), and summing up the total area for all size classes. Scab area measurements were subjected to two-way analysis of variance for a completely randomized design (SAS Institute, Inc., Cary, NC). A $P$ level of 0.05 was considered statistically significant.

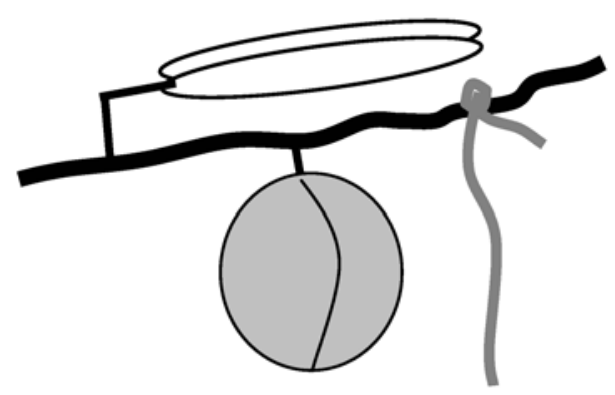

Fig. 1. Schematic representation of a peach fruit with a rain shield to prevent splash and a cotton wick to intercept twig runoff and prevent it from reaching the fruit in orchard conditions.
To ascertain the effect of the shield and wick treatments in reducing water supply to fruit, another 200 fruit were selected randomly in the orchard at calyx fall. The fruit were removed and each replaced with a $15-\mathrm{ml}$ polypropylene centrifuge tube attached to the twig with steel wires such that the opening of the tube (15 $\mathrm{mm}$ in diameter) was located directly beneath the peduncle of the removed fruit. Tubes were assigned randomly to the shield, wick, combined shield-wick, and control treatments described above. Following each of six rain events during the periods 24 to 28 April (9.9 mm of rain), 3 to 4 May $(8.4 \mathrm{~mm}), 21$ to 25 May (18.5 mm), 5 June ( $4.8 \mathrm{~mm}), 16$ to 18 June $(6.4 \mathrm{~mm})$, and 25 to 29 June $(55.6 \mathrm{~mm})$, tubes were removed from the orchard temporarily to measure the volume of water collected within them. If large amounts of water were present, volumes were determined directly using the graduation marks on the tubes. Small volumes were measured using hand-held pipettes, with the smallest volume that could be measured reliably being $0.04 \mathrm{ml}$. Trace amounts of water too small for measurement were assigned a volume of $0.02 \mathrm{ml}$. Average volumes were calculated for each treatment across the six rain events.

Year 2001 and 2002 experiments. The experiments were carried out in a different block of the same orchard used in 2000. As part of fungicide evaluation trials, certain areas of the block had received a routine scab control program (10) during the previous year (either 2000 or 2001), whereas no fungicides had been applied in other areas. The rareness of scab twig lesions in the previously sprayed trees implied that fruit infection in these trees would occur primarily by airborne conidia from unsprayed trees nearby (located within the same tree row or the adjacent row). By contrast, scab twig lesions were numerous in previously unsprayed trees, and fruit infection could occur by short-distance waterborne dissemination of conidia from twig lesions in the same trees, in addition to the aerial dissemination mentioned above.

In both areas, individual fruit were selected at calyx fall and equipped with or without rain shields or cotton wicks as described above. Compared with 2000, two additional treatment designs with adjustable rain shields were included, in one of which shields were manually put in "closed" position to cover the fruit only before rain events; after the rain, the shields were "opened" again. This arrangement prevented rain splash from reaching the fruit, but allowed dew formation on the fruit surface during clear nights. In the other new treatment, this layout was applied in reverse order (i.e., the shield was opened during rain and closed otherwise, to allow splash but prevent dew formation). Various combinations of the shield and wick treatments were implemented in the previously sprayed and unsprayed areas (Fig. 2). Comparison of fruit scab severity between individual treatments allowed us to untangle the relative contributions of various fruit wetness sources (dew, splash, runoff) and means of conidial dissemination (airborne, or waterborne in splash or runoff) to disease development in orchard conditions.

In the treatments with adjustable shields, it was not always possible to open or close the shields at the exact times of onset and end of each rain event. For example, when rain was predicted to occur at night, shields often were placed in their respective rain positions when clouds began to gather during the late afternoon or evening. The purpose of the adjustable shields was to either selectively allow or prevent dew from forming on the fruit; therefore, the error associated with premature adjustment of shield position was likely small, given that condensation is limited or absent during overcast nights. Similarly, the error made by not readjusting shield position immediately following a rain event was likely small because cloud cover usually persisted for several hours after the rain.

Each of the nine treatments illustrated in Figure 2 consisted of 40 fruit at the beginning of the experiment. As in 2000, some fruit loss due to brown rot occurred throughout the season. At harvest, the scabbed area on each fruit was measured as described above. 
Effects of individual fruit wetness sources or means of dissemination were determined by linear contrasts between selected treatments (Table 1).

Year 2003 experiment. In order to examine the importance of aerial dissemination of conidia more directly, a 7-day volumetric spore sampler (Burkard Mfg. Co. Ltd., Rickmansworth, England) was operated in a block of the orchard that had not received fungicide applications the previous years and remained unsprayed throughout the 2003 growing season. The sampler was placed within a tree row where the drip lines of two adjacent trees overlapped, with the orifice positioned at a height of $1.3 \mathrm{~m}$. The instrument was operated continuously for 8 weeks starting at petal fall; this period corresponds to the phase of peak conidial production of C. carpophilum on twig lesions $(3,12,24)$. Spore sampler tapes were retrieved weekly, cut into daily segments, mounted on glass slides, stained with trypan blue in lactic acid, and examined microscopically $(\times 200)$. Conidia of $C$. carpophilum were identified based on morphological features (21) in conjunction with a reference slide made from conidia removed from a scab twig lesion. Counts were made in three linear transects along each tape segment and were converted to numbers of conidia per cubic meter and day based on the sampler's air intake rate (10 liters/min) and the proportion of each tape segment that was examined microscopically.

\section{RESULTS}

Cumulative rainfall during the experimental period from petal fall to harvest, as recorded by an electronic weather station located within $500 \mathrm{~m}$ of the orchard, was lowest $(155 \mathrm{~mm})$ in 2000 (Fig. 3). Values were considerably higher in 2001 (316 mm) and 2002 (334 mm). Rainfall patterns affected scab development across the 3 years; scab severity on untreated control fruit was lowest in $2000\left(194.5 \mathrm{~mm}^{2}\right.$ of scab surface area) and greatest in $2001\left(616.0 \mathrm{~mm}^{2}\right)$ (Figs. 4 and 5).

Year 2000 experiment. Across the six rain events examined for the effects of the shield and wick treatments on water supply to centrifuge tubes attached to twigs from which fruit had been removed, the combined shield-wick treatment had the most pronounced effect, allowing no water to enter the tubes (Fig. 4A). The presence of shields (excluding only splash) and wicks (excluding only twig runoff) reduced water supply by 91.8 and

\begin{tabular}{|c|c|c|c|c|c|c|}
\hline \multirow{2}{*}{} & \multicolumn{2}{|c|}{$\begin{array}{c}\text { Trees with fungicide program in the } \\
\text { previous growing season } \\
\text { (low density of twig lesions) }\end{array}$} & \multicolumn{2}{|c|}{$\begin{array}{r}\text { Trees without fungicide program in } \\
\text { the previous growing season } \\
\text { (high density of twig lesions) }\end{array}$} \\
\cline { 2 - 7 } & Trtmt. & $\begin{array}{c}\text { Inoculum } \\
\text { source }\end{array}$ & $\begin{array}{c}\text { Wetness } \\
\text { source }\end{array}$ & Trtmt. & $\begin{array}{c}\text { Inoculum } \\
\text { source }\end{array}$ & $\begin{array}{c}\text { Wetness } \\
\text { source }\end{array}$ \\
\hline & 1 & Air & None & & & \\
\hline & 2 & Air & Dew & & $\begin{array}{c}\text { Air } \\
\text { Splash }\end{array}$ & \begin{tabular}{c} 
Splash \\
\hline
\end{tabular} \\
\hline
\end{tabular}

Fig. 2. Schematic representations of nine treatments used to manipulate fruit surface wetness sources and means of conidial dissemination of Cladosporium carpophilum on individual peach fruit in orchard conditions in 2001 and 2002. Rain shield position was fixed in treatments 1 and 9 but was adjustable in treatments 2,3 , and 6 . The dashed lines in treatments 2,3 , and 6 indicate positions during rain events, whereas the solid lines correspond to positions before and after rain.

TABLE 1. Linear contrasts to determine the effects of fruit wetness sources and means of conidial dissemination on scab severity caused by Cladosporium carpophilum on peach fruit in orchard conditions in 2001 and 2002

\begin{tabular}{|c|c|c|c|c|c|}
\hline \multirow[b]{2}{*}{ Treatment comparison ${ }^{\mathrm{a}}$} & \multirow[b]{2}{*}{ Effect analyzed } & \multicolumn{2}{|c|}{2001} & \multicolumn{2}{|c|}{2002} \\
\hline & & $F$ & $P$ & $F$ & $P$ \\
\hline 1 versus 5 & Exclusion of all fruit wetness sources in the absence of waterborne conidia & 0.61 & 0.4353 & 0.17 & 0.6802 \\
\hline 7 versus 8 & Exclusion of twig runoff & 13.1 & 0.0005 & 4.4 & 0.0387 \\
\hline 6 versus 9 & Relative importance of splash versus runoff & 14.5 & 0.0002 & 19.2 & $<0.0001$ \\
\hline 6 versus 7 & Exclusion of dew in the presence of other fruit wetness sources & 0.52 & 0.4718 & 0.35 & 0.5552 \\
\hline
\end{tabular}

a Treatments described in Figure 2. 
$38.7 \%$, respectively, compared with the untreated control. Thus, it may be concluded that the experimental treatments were effective in manipulating water supply to the fruit.

Trends in disease severity in relation to the four treatments closely mirrored their effects on water supply (Fig. 4B). In the presence of shields, fruit scab severity was reduced considerably (by $96.8 \%)$ and significantly $(P<0.0001)$ compared with the untreated control (Table 2). Cotton wicks upstream of the peduncle reduced disease severity by $38.4 \%$, but this effect was not statistically significant $(P=0.1117)$. There was no significant interaction between the shield and wick treatments (Table 2).

Year 2001 and 2002 experiments. In both years, fruit scab severity on trees in areas with a standard fungicide program the previous year was very low, regardless of presence or absence of shields or wicks (Fig. 5, treatments 1 through 5). This indicates
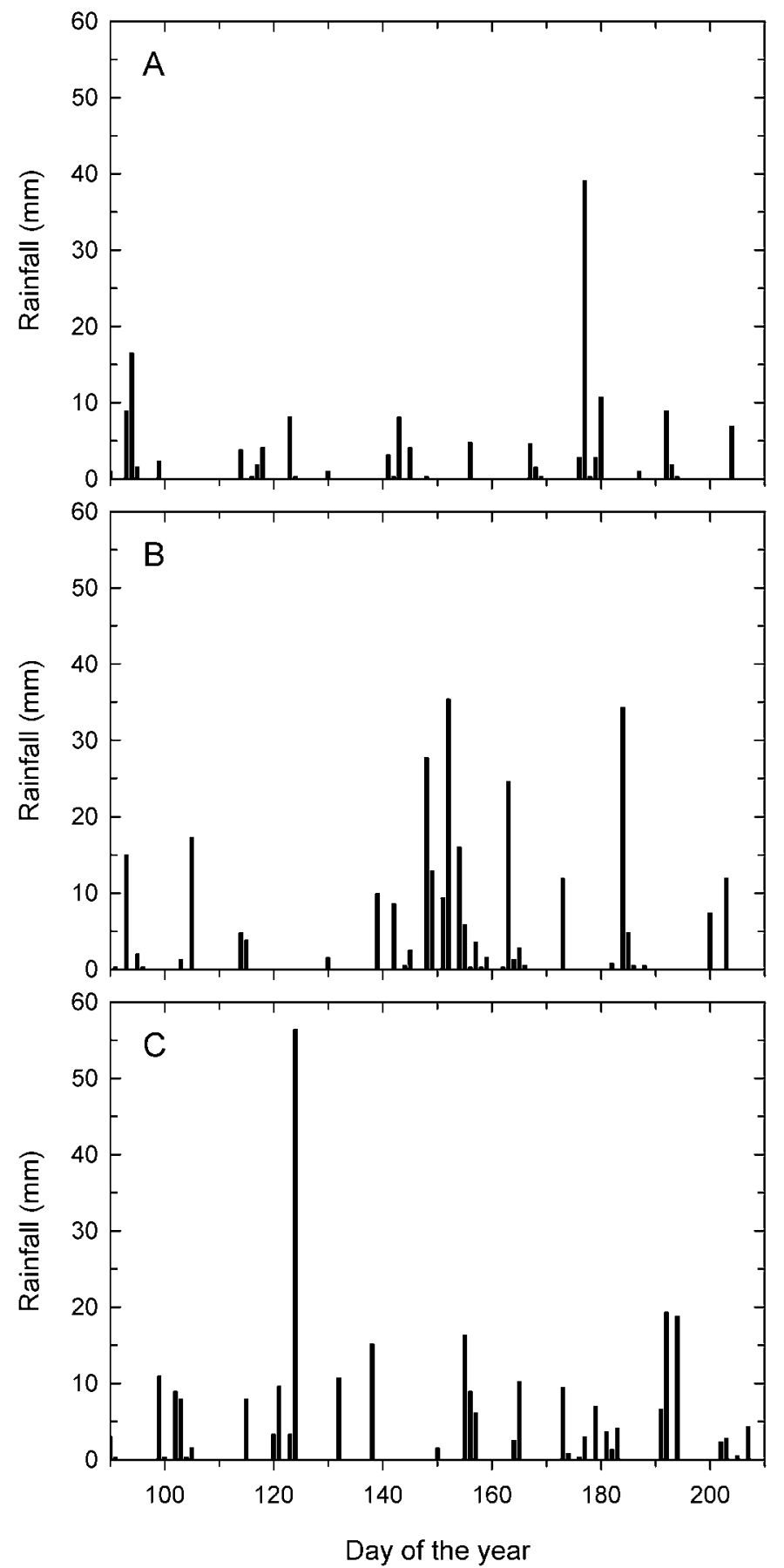

Fig. 3. Daily rainfall in the study orchard in A, 2000, B, 2001, and C, 2002. Data are given for the period from petal fall to fruit harvest. that airborne conidia from nearby trees that were unsprayed the previous year were of limited importance in scab development. This conclusion is supported by the observation that scab severity in treatment 5 (untreated control) was not significantly different from that in treatment 1 (where all fruit wetness sources were excluded by combined use of shields and wicks) (Fig. 5; Table 1); if there had been large numbers of airborne conidia, disease severity in the former treatment should have been higher.

With the exception of treatment 9 , in which fruit were protected by shields throughout the experimental period, fruit scab severity was considerably higher on trees in areas that were unsprayed the previous year compared with those that received a standard fungicide program during that period (Fig. 5). A comparison between treatments 8 and 5, the untreated controls in both areas, illustrates this point. Scab severity was significantly $(P<0.0001)$ higher in treatment 8 (Table 1), the fruit of which were exposed to waterborne conidia from splash and runoff as an additional means of inoculum dissemination due to the localized presence of twig lesions (Fig. 2). This result documents the importance of waterborne conidia for scab development.

The role of splash as a component of waterborne inoculum may be deduced by contrasting treatments 3 and 4 with 6 and 7, in all of which runoff was excluded. Treatments 6 and 7 had splashing as an additional means of inoculum dissemination (Fig. 2), resulting in a highly significant $(P<0.0001)$ increase in disease severity (Table 1).

The treatments depicted in Figure 2 did not allow the role of runoff in conidial dissemination to be separated from its role as a fruit wetness source. However, its overall effect on scab development could be analyzed by comparing treatments 7 and 8 . Exclu-

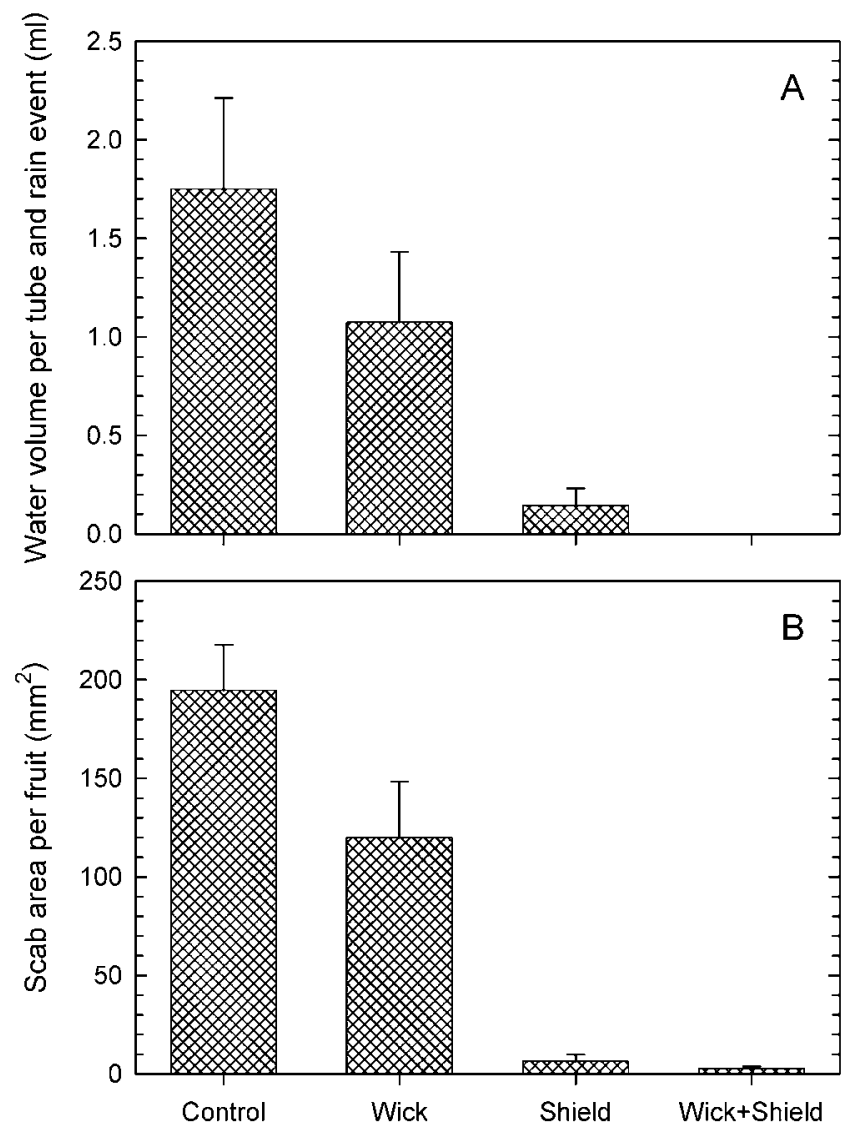

Fig. 4. Effect of rain shields and cotton wicks on $\mathbf{A}$, water supply and $\mathbf{B}$, scab severity caused by Cladosporium carpophilum and individual peach fruit cv. Blake in 2000. Water volume was measured during six rain events on twigs from which fruit had been removed and replaced with $15-\mathrm{ml}$ polypropylene centrifuge tubes attached directly beneath the peduncle. Values are means and standard errors for each treatment. 
sion of runoff in the former treatment resulted in significantly $(P<0.05)$ lower fruit scab levels (Table 1). Indeed, affected fruit surface areas in treatment 7 were reduced by 44.9 and $31.6 \%$ compared with those in treatment 8 in 2001 and 2002, respectively.

A comparison between treatments 6 and 9 allowed the relative importance of splash and runoff to be assessed (Fig. 2). Fruit receiving inoculum and wetness exclusively via runoff (treatment 9) had significantly less scab than those receiving inoculum and wetness exclusively via splash (treatment 6), indicating that splash was more important (Table 1).

Dew differs from splash and runoff in that it serves only as a fruit wetness source, not as a means of conidial dissemination. Relative to treatment 7, dew was excluded from fruit in treatment 6 by an adjustable shield that was in open position only during rain. Similar levels of scab in the two treatments $(P=0.4718$ and 0.5552 in 2001 and 2002, respectively) suggest that dew played a limited role in scab development in the presence of other fruit wetness sources (Table 1).

Year 2003 experiment. Densities of airborne conidia of $C$. carpophilum remained very low throughout the experimental period (Fig. 6), with an average of $<1$ conidium $/ \mathrm{m}^{3}$ and day trapped. Nonetheless, a severe fruit scab epidemic developed in the orchard $\left(>1,000 \mathrm{~mm}^{2}\right.$ of scab surface area on untreated fruit), suggesting that the conidia responsible for this epidemic likely arrived by means other than aerial dissemination.

\section{DISCUSSION}

Previous reports provided conflicting information regarding the relative importance of air- versus waterborne dissemination of conidia of C. carpophilum $(6,12,16)$. In this study, analysis of scab severity on individual fruit on which wetness sources and means
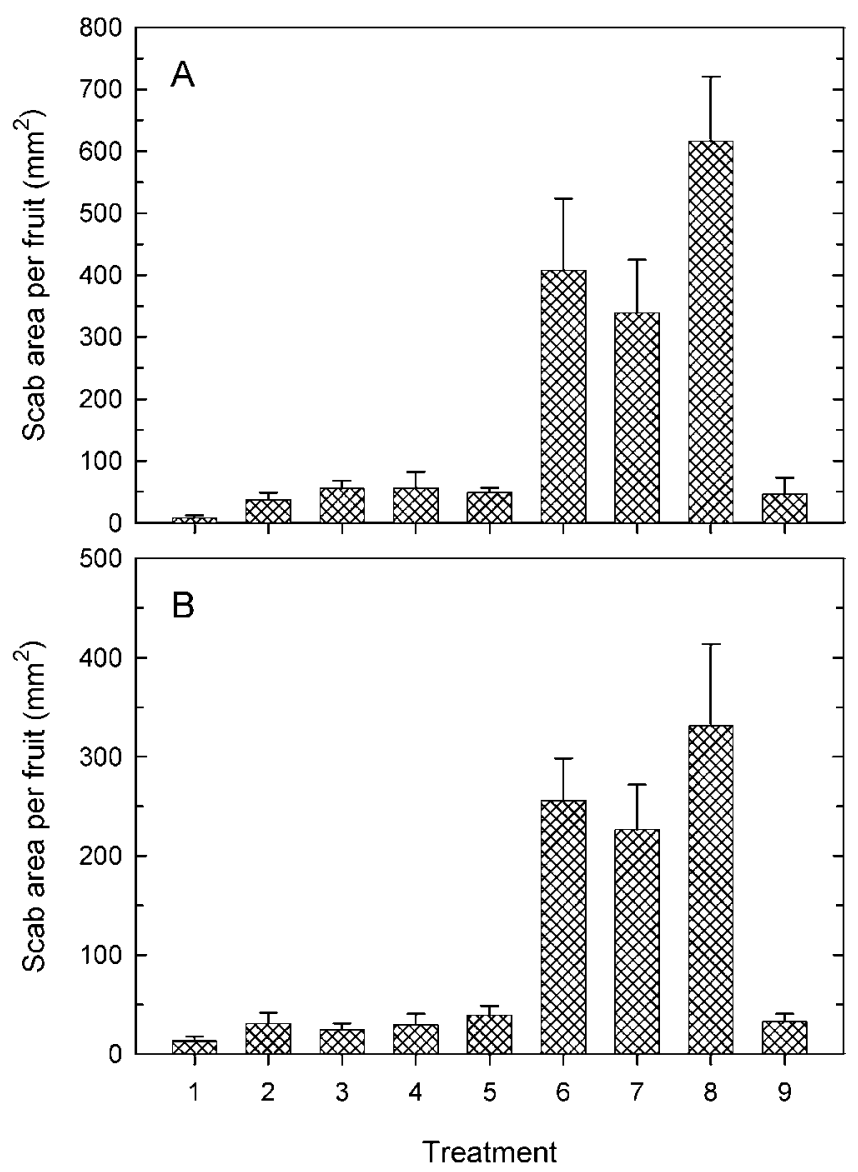

Fig. 5. Effect of rain shields and cotton wicks on scab severity caused by Cladosporium carpophilum on individual peach fruit cv. Blake in A, 2001 and $\mathbf{B}, 2002$. Values are means and standard errors for each treatment. of conidial arrival were manipulated revealed that rain splash contributed most to disease development. This was due, at least in part, to the fact that splash was the most prominent means of conidial dissemination. This finding supports Keitt's assertion that waterborne inoculum results in a large majority of fruit infections in the orchard (12), although he did not attempt to separate the relative contributions of splash and runoff.

Rain splash is an important means of conidial dissemination for many fungal plant pathogens, primarily those that produce spores in mucilage in asexual fruiting structures such as sporodochia, pycnidia, or acervuli $(4,9,18)$. C. carpophilum does not form such fruiting structures; instead, conidia are produced freely on stromatoid layers of pseudoparenchymatous mycelial masses. Nonetheless, the conidia are so firmly attached that they are not easily liberated by wind (12). This is similar to Rhynchsporium secalis, another hyphomycete which also forms conidia on a stroma and in which conidia are primarily waterborne rather than airborne (1).

Splash droplets generally move in ballistic trajectories; thus, conidia in splash disperse only short distances $(4,18)$. This is consistent with orchard observations that fruit infection by $C$. carpophilum is more severe when twig lesions are closer to the fruit peduncle (12).

Water runoff on tree canopy elements plays an important role in the redistribution of rain in orchards. In citrus tree canopies, interception by the canopy and runoff via the trunk accounted for 5.8 to $9.3 \%$ and 0.5 to $4.7 \%$ of the incident rainfall, respectively (17). In an apple orchard, $\approx 1 \%$ of rainfall was diverted to trunk stem flow (2). Whereas runoff from twigs was not measured in these studies, it is reasonable to assume that the volume of water diverted to twig runoff is greater than that in trunk stem flow. Nonetheless, twig runoff as a means of conidial dissemination has received little attention. Two previous studies on peach scab sug-

TABLE 2. Analysis of variance to determine the effects of presence or absence of rain shields and cotton wicks on scab severity caused by Cladosporium carpophilum on peach fruit in orchard conditions in $2000^{\text {a }}$

\begin{tabular}{lrrrr}
\hline Source & df & MS & $F$ & $P$ \\
\hline Shield & 1 & 671,183 & 39.1 & $<0.0001$ \\
Wick & 1 & 44,069 & 2.57 & 0.1117 \\
Shield-wick & 1 & 36,413 & 2.12 & 0.1479 \\
Error & 124 & 17,173 & $\ldots$ & $\ldots$
\end{tabular}

a Shields and wicks attached to the twig excluded rain splash and runoff from fruit, respectively.

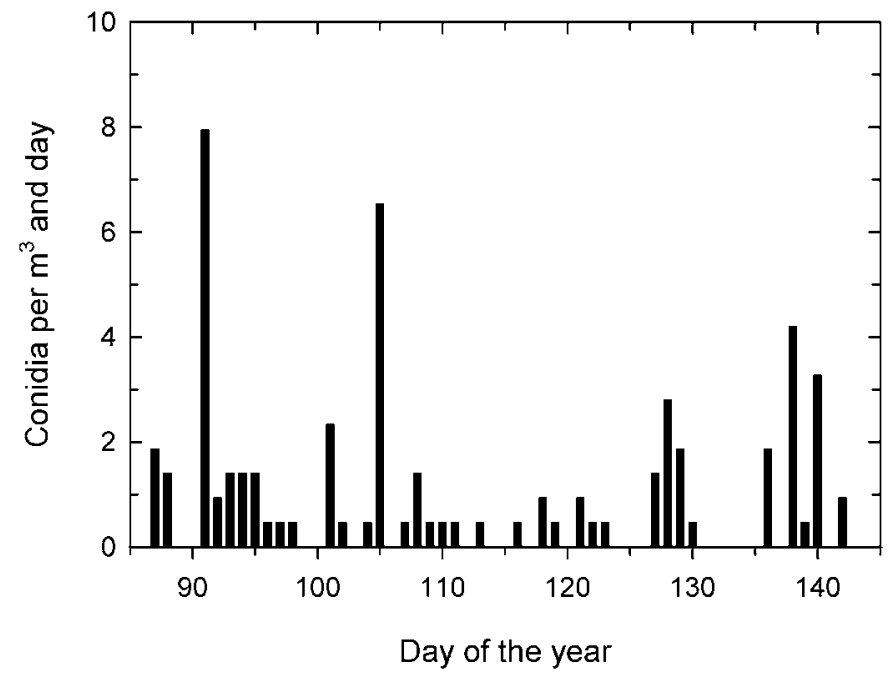

Fig. 6. Daily densities of airborne conidia of Cladosporium carpophilum determined with a volumetric spore sampler in the study orchard in 2003. Data are given for an 8-week period starting at petal fall; this period corresponds to the phase of peak conidial production of $C$. carpophilum. 
gested an association between runoff and conidial dissemination or fruit disease development, but the relative contribution of runoff to these processes was not quantified. Lawrence and Zehr (16) found that conidia of $C$. carpophilum were abundant in runoff from infected peach twigs, whereas Keitt (12) noted that fruit on horizontally oriented twigs generally had less severe scab, presumably because the passage of water to the fruit via the peduncle was reduced on such twigs.

In the present study, exclusion of runoff with cotton wicks reduced disease severity by 31.6 to $44.9 \%$. Nonetheless, as evidenced by the 2000 experiment, this effect was not always statistically significant. Moreover, fruit from which rain and dew were excluded by rain shields had very low disease levels, despite the presence of runoff as a wetness and inoculum source (treatment 9 in 2001 and 2002). Conidia transported to the fruit surface via runoff may be of limited effectiveness unless provided with additional sources of fruit wetness such as splash and dew.

Airborne conidia contributed little to scab development on peach fruit in the present study. This is consistent with the failure to dislodge significant numbers of conidia of $C$. carpophilum in wind tunnel experiments in the laboratory $(6,12)$. Indeed, windassisted conidial discharge by $C$. carpophilum was appreciable only at $\mathrm{RH}<40 \%$, especially when $\mathrm{RH}$ dropped rapidly from near saturation (6). Such environmental conditions are rare in orchards in the southeastern United States. In field conditions, a previous spore-trapping study with benomyl-amended culture media in a South Carolina orchard readily detected colonies of Cladosporium spp. from the air (16), but these colonies were not confirmed to be C. carpophilum. By contrast, our spore-trapping study with direct microscopic examination of the spore sampler tapes revealed a very low density of airborne conidia of $C$. carpophilum, despite the very high inoculum pressure in the test orchard. This finding is consistent with the conclusion of a limited role of aerial dissemination of conidia derived from the other experiments reported here.

The dominant influence of waterborne inoculum on fruit scab development warrants future experiments on the effects of rain intensity and duration on conidial dissemination by splash and runoff in relation to twig orientation (e.g., twig angle and distance between scab lesion and fruit peduncle). Moreover, it would be of interest to characterize the relative distribution of rain among throughfall, splash, and runoff for different orchard training systems to identify those systems that minimize splashing. In terms of disease management, our results suggest that scab severity may be reduced on fruit with limited exposure to splash and runoff (i.e., those borne on distal sections of upright twigs). Unfortunately, this can be manipulated only to a limited degree through currently used training, pruning, and thinning practices.

\section{ACKNOWLEDGMENTS}

Funded in part by the United States Environmental Protection Agency Region 4 Pesticide Environmental Stewardship Program. We thank A. Savelle for technical assistance.

\section{LITERATURE CITED}

1. Ayesu-Offei, E. N., and Carter, M. V. 1971. Epidemiology of leaf scald of barley. Aust. J. Agric. Res. 22:383-390.

2. Calheiros de Miranda, R. A., and Butler, D. R. 1986. Interception of rainfall in a hedgerow apple orchard. J. Hydrol. 87:245-253.

3. Cook, M. J., and Scherm, H. 1999. Antisporulant activity of early-season fungicide sprays against peach scab, 1998. F\&N Tests 54:53.

4. Fitt, B. D. L., McCartney, H. A., and Walklate, P. J. 1989. The role of rain in dispersal of pathogen inoculum. Annu. Rev. Phytopathol. 27:241-270.

5. Gottwald, T. R. 1982. Spore discharge by the pecan scab pathogen, Cladosporium caryigenum. Phytopathology 72:1193-1197.

6. Gottwald, T. R. 1983. Factors affecting spore liberation by Cladosporium carpophilum. Phytopathology 73:1500-1505.

7. Gottwald, T. R., and Bertrand, P. F. 1982. Patterns of diurnal and seasonal airborne spore concentrations of Fusicladium effusum and its impact on a pecan scab epidemic. Phytopathology 72:330-335.

8. Hendrix, F. F., Jr. 1995. Scab. Pages 11-12 in: Compendium of Stone Fruit Diseases. J. M. Ogawa, E. I. Zehr, G. W. Bird, D. F. Ritchie, K. Uriu, and J. K. Uyemoto, eds. The American Phytopathological Society, St. Paul, MN.

9. Hörberg, H. M. 2002. Patterns of splash dispersal of conidia of Fusarium poae and Fusarium culmorum. Eur. J. Plant Pathol. 108:73-80.

10. Horton, D. L., Gorsuch, C., and Ritchie, D. 2001. 2001 Southern Peach, Nectarine and Plum Pest Management and Culture Guide. Cooperative Extensive Service, University of Georgia, Athens.

11. Jordan, M. M., Burchill, R. T., and Maude, R. B. 1990. Epidemiology of Cladosporium allii and Cladosporium allii-cepae, leaf blotch pathogens of leek and onion. I. Production and release of conidia. Ann. Appl. Biol. 117:313-326.

12. Keitt, G. W. 1917. Peach scab and its control. U.S. Dep. Agric. Bull. 395:1-66.

13. Lan, Z., and Scherm, H. 2002. Moisture sources in relation to conidial dispersal and infection by Cladosporium carpophilum within peach canopies. (Abstr.) Phytopathology 92(suppl.):S44.

14. Lan, Z., Scherm, H., and Horton, D. L. 2003. Reduced midseason pesticide program for control of scab and plum curculio in peach. Plant Dis. 87:699-706.

15. Latham, A. J. 1982. Effects of some weather factors and Fusicladium effusum conidial dispersal on pecan scab occurrence. Phytopathology 72:1339-1245

16. Lawrence, E. G., Jr., and Zehr, E. I. 1982. Environmental effects on the development and dissemination of Cladosporium carpophilum on peach. Phytopathology 72:773-776.

17. Li, Y. C., Alva, A. K., Calvert, D. V., and Zhang, M. 1997. Stem flow, throughfall, and canopy interception of rainfall by citrus tree canopies. HortScience 32:1059-1060.

18. Madden, L. V. 1992. Rainfall and the dispersal of fungal spores. Adv. Plant Pathol. 8:39-79.

19. Miller, R. W., and Bertrand, P. 1985. Peach scab. Pages 113-115 in: Peach Production Handbook. S. C. Myers, ed. Cooperative Extension Service, University of Georgia, Athens.

20. Pady, S. M., Kramer, C. I., and Clay, R. 1969. Periodicity in spore release in Cladosporium. Mycologia 61:87-98.

21. Partridge, E. C., and Morgan-Jones, G. 2003. Notes on Hyphomycetes. XC. Fusicladosporium, a new genus for Cladosporium-like anamorphs of Venturia and the pecan scab-inducing fungus. Mycotaxon 85:357-370.

22. Rich, S., and Waggoner, P. E. 1962. Atmospheric concentration of Cladosporium spores. Science 137:962-965.

23. Scherm, H., and Savelle, A. T. 2001. Control of peach scab with reduced mid-season fungicide programs. Plant Dis. 85:706-712.

24. Scherm, H., Savelle, A. T., Boozer, R. T., and Foshee, W. G. 2003. Seasonal dynamics of conidial production in the peach scab fungus Cladosporium carpophilum. (Abstr.) Phytopathology 93(suppl.):S76. 